\title{
Countertransference feelings and personality disorders: A psychometric evaluation of a brief version of the Feeling Word Checklist (FWC-12)
}

Randi Breivik ( $\nabla$ randi.breivik@medisin.uio.no)

Oslo universitetssykehus Ulleval https://orcid.org/0000-0001-7665-3014

Theresa Wilberg

Oslo University Hospital

Julie Evensen

Oslo University Hospital

Jan Ivar Røssberg

Oslo University Hospital and University of Oslo

Hanne Sofie Dahl

Vestfold Hospital Trust and University of Oslo

Geir A. Feigum Pedersen

Oslo university hospital and University of Oslo

\section{Research article}

Keywords: Countertransference, Feeling Word Checklist, factor analysis, personality disorder, psychometrics

Posted Date: November 20th, 2019

DOI: https://doi.org/10.21203/rs.2.17558/v1

License: (1) (1) This work is licensed under a Creative Commons Attribution 4.0 International License. Read Full License

Version of Record: A version of this preprint was published at BMC Psychiatry on March 30th, 2020. See the published version at https://doi.org/10.1186/s12888-020-02556-6. 


\section{Abstract}

Background The Feeling Word Checklist (FWC) is a self-report questionnaire designed to measure therapists' countertransference (CT) feelings. The primary aim of the study was to evaluate the psychometric properties of a brief version of the Feeling Word Checklist comprising twelve feeling words (FWC-12). The second aim was to validate the factor structure by examining the associations between the FWC-12 factors, patients' personality pathology and therapeutic alliance (TA).

Methods Therapists at 13 different outpatient units within the Norwegian Network of Personality Disorders completed the FWC-12 every 6 months during the course of treating a patient with a personality disorder (PD), over a period of up to 2.5 years. A large sample of patients with personality pathology participated in the study. The data were analysed with exploratory (EFA) and confirmatory (CFA) factor analysis. Internal consistency was estimated using Cronbach's alpha. The Structured Clinical Interview for DSM-IV - Axis II (SCID II) and Mini International Neuropsychiatric Interview (MINI) were used as diagnostic instruments, and patient-rated TA was assessed using the Working Alliance Inventory (WAI$\mathrm{SR})$.

Results Factor analyses revealed three clinically meaningful factors: Inadequate, Idealised and Confident. These factors had acceptable psychometric properties. Most notably, a number of borderline PD criteria correlated positively with the factors Inadequate and Idealised, and negatively with the factor Confident. All the factors correlated significantly with at least one of the WAI-SR subscales.

Conclusions The FWC-12 measures three clinically meaningful aspects of therapists' CT feelings. This brief version of the FWC seems satisfactory for use in further research and in clinical contexts. Keywords: Countertransference, Feeling Word Checklist, factor analysis, personality disorder, psychometrics

\section{Background}

Freud first introduced the term countertransference $(C T)$ to refer to an analyst's transference to the patient (1). That is, therapists unconsciously displace feelings from their past onto analytic situations. Ideally, this is not supposed to happen; analysts are supposed to stay calm and objective, allowing no personal material to interfere with therapy. In this narrow Freudian view, CT is essentially an obstacle to be overcome, arising from therapists' own unresolved conflicts. Freud's solution was for therapists to undergo more self-analysis to get rid of these disturbing feelings. Since then, the concept of CT has broadened, instead being seen as a road to knowledge about the patients' problems, as patients communicate something important about their inner world with the feelings they induce in their therapist. In this broader view, CT is understood as all the feelings evoked in the therapist, both conscious and unconscious $(2,3)$. The contemporary view of CT has expanded to encapsulate both the narrow and the broad view, seeing CT as a co-creation between therapist and patient (4).

Although the concept of CT originally derives from psychoanalytic theory, several current psychotherapeutic approaches regard the therapist's emotional reactions as an important aspect of the 
therapeutic process (5-7). However, empirical work on CT has historically been sparse compared to the enormous amount of theoretical literature written about the phenomenon. A main challenge in the development of systematic research has been the lack of a common definition of CT. Additionally, CT is partly an unconscious phenomenon and is therefore difficult to assess. Nevertheless, the existing empirical research shows that CT can be measured in ways that capture much of the complexity of what the therapist is experiencing $(5,8,9)$.

Two approaches have been used to measure CT empirically. One is to have therapists fill out self-report questionnaires $(8,10)$. The other is to have an external observer evaluate recorded material from sessions $(11-13)$. One of the benefits of using questionnaires is their quantitative nature; they can be distributed to many therapists, and one can subsequently receive large amounts of experienced feelings that can be used to identify common patterns of feelings (18). The Feeling Word Checklist (FWC) $(10,14,15)$, in various versions, is one of the most used questionnaires for research on CT (16).

\section{The FWC}

In the FWC, therapists are given a list of feeling words and must check off the feelings they have experienced in relation to a patient. The first version of the FWC was developed by Whyte et al. (10) and comprised 30 feeling words. Later, different versions of the questionnaire were developed that include between 24 and 58 feeling words. These different versions were created, in part, to include feeling words that experienced therapists found to be missing from the original list and to enhance the stability of the underlying factors in the FWC (17). Different research groups have identified different factors underlying the words in the FWC, and between three and seven factors are described in other studies. Variations in the number of factors used may be explained by the use of different versions of the FWC and dissimilar scale formats, such as multiple response-point Likert scales or dichotomous yes/no versions (15).

The statistical methods used to evaluate them have also varied; while most studies have used principal component analyses, some have used factor analyses (9). Furthermore, the studies conducted have involved therapists of diverse professions, different patient populations and large heterogeneous groups. The first studies using FWC were performed in inpatient departments. More recent studies have examined the factor structure when FWC is applied in individual therapy $(9,17-19)$. There is still no consensus about which FWC version best captures the CT phenomenon. Generally, all studies have found at least one factor reflecting positive feelings and at least one reflecting negative feelings (9). One goal in the CT research is to find many of the same feeling factors, as this may support that important aspects of CT have been captured. So far, many of the factors in the FWC overlap.

In our study, we used a brief FWC version that features only 12 feeling words (FWC-12). A brief version is easier to implement in clinical contexts, thus facilitating the psychotherapy process and outcome research. An instrument such as the FWC-12 can also help therapists become more aware of their feelings. Several studies have demonstrated that therapists' feelings are related to patient outcomes ( 7 , 20). For therapists to become aware of this phenomenon, it must be given attention. There is a need for 
research on the psychometric properties of instruments used in CT research to make future studies more robust (21). A brief questionnaire, such as the FWC-12, will obviously not capture all important CT feelings, but it can provide insight into meaningful aspects or patterns of feelings.

\section{CT and Personality Pathology}

Because of the relational strain often reported by therapists working with patients who have a personality disorder (PD), there is extensive clinical and theoretical literature on $\mathrm{CT}$ and patients with PD. Particularly, many clinical articles are about borderline PD. Kernberg (22) described that these patients tend to elicit powerful CT reactions in therapists because of their intense, primitive and regressive transferences. Furthermore, it has been argued that specific CT feelings are the most reliable guide to diagnose borderline PD, such as the feeling of being idealised or devaluated as a therapist. There are, however, few empirical studies on PD and CT $(5,23-26)$. Two studies have explored therapists' feelings in relation to Diagnostic and Statistical Manual of Mental Disorders Version 4 (DSM-IV) diagnoses at the PD cluster level and found that that patients with cluster A (i.e., paranoid, schizoid and schizotypal PD) and B (i.e., antisocial, borderline, histrionic and narcissistic PD) elicited more negative CT feelings than did patients with cluster $C$ disorders (i.e., avoidant, dependent and obsessive compulsive PD) $(5,23)$. Some studies (5, 24) have found that specific PD categories elicit different CT feelings in therapists. For example, in the study by Colli et al. (24), borderline PD was associated with emotional response feelings such as Helpless/Inadequate, Overwhelmed/Disorganised and Special/Overinvolved, while avoidant PD was associated with Parental/Protective and Special/Overinvolved responses. This study indicated that therapists' feelings can nearly be applied diagnostically. A few studies have looked at PD dimensionally in terms of number of fulfilled PD criteria and CT feelings. Dahl et al. (17), for example, found a strong negative relationship between the total number of fulfilled PD criteria and confident $C T$.

\section{CT and Therapeutic Alliance (TA)}

The term therapeutic alliance (TA) refers to the working relationship between the therapist and patient. To date, only a few studies have investigated the relationship between TA and CT $(13,17,21,27)$. Both the TA measurement instruments and results of these studies vary widely. Existing studies also differ in terms of whether TA is patient-rated, therapist-rated or based on both perspectives. To summarise, two studies reported a negative correlation between negative aspects of CT feelings and TA $(13,21)$, while others found both negative correlations between negative CT feelings and TA and positive correlations between positive CT feelings and TA $(17,27)$.

\section{Aims of the Present Study}

The patient populations used in many past studies on CT have been heterogeneous, and many have included a small number of patients. Very few studies have been based on a selection of poorly functioning patients with PD. This study consists of a large sample of patients with significant PD 
pathology. In this way, it may be possible to examine the feelings that therapists can experience while working with a varied sample of PD patients.

The primary aim of the current study is to explore the factor structure and psychometric properties of the FWC-12, used in a clinical sample of patients with PD or PD traits. Our secondary aim is to validate these factors by examining their relationship with patients' personality pathology and TA.

More specifically, we wanted to answer the following research questions:

- How many clinically meaningful factors do the items in the FWC-12 represent?

- What is the relationship between therapists' CT feelings, assessed by FWC-12, and patients' personality pathology?

- What is the relationship between therapists' CT feelings, assessed by FWC-12, and patient-rated TA?

\section{Methods}

\section{Participants}

\section{Therapists}

In this multi-site, naturalistic and explorative study, the material comprised data from 13 outpatient units in the Norwegian Network of Personality Disorders (28) from 2010 to 2016. All units were specialised in the treatment of PD and personality-related interpersonal difficulties. The different units offered various forms of group-based treatment programs, such as psychodynamic, mentalisation-based, cognitive, dialectic behavioural, psychoeducational and body awareness groups. Some programs offered combined group and individual therapy. The length of the treatment programs varied from short-term to long-term, up to a duration of three years. Staff within the units were typically multidisciplinary, including psychiatrists, psychologists, psychiatric nurses and social workers, experienced in the treatment of patients with PD. Most of the therapists had further education in group psychotherapy. Group supervision of the therapists is traditionally an important element in treatment programs, and CT is part of the clinical discussions. The therapists filled out the FWC-12 at 6-month intervals about a patient they had in treatment (i.e., from 6 months up to 2.5 years), with a final assessment at end of the patient's treatment.

\section{Patients}

A total of 2,425 adult patients participated in this study. The mean age was 33 years (standard deviation [SD] $=10$ years), and $76 \%$ of the patients were female. According to the guidelines given in DSM-IV (29), $71 \%$ of participants had one or more PD diagnosis and $94 \%$ had at least one symptom disorder, wherein $68 \%$ had mood disorders and $57 \%$ had anxiety disorders (see Table 1 for prevalence of PDs). The severity of PD is illustrated through different outcome measures: the Global Assessment of Functioning (GAF; 
APA, 1994) and Work and Adjustment Scale (WSAS) (30) measure patient psychosocial functioning; the Global Severity Index (GSI) measures symptom distress and is the mean score of the Revised Symptom Checklist-90 (SCL-90-R) (31); and the Index of Interpersonal Problems (IIP) measures interpersonal problems and is the mean score of the Circumplex of Interpersonal Problems (CIP) (32). The CIP is a revised version of the Inventory of Interpersonal Problems-Circumplex (IIP-C) (33).

In the current study, the mean GAF score was $49.77(\mathrm{SD}=6.06)$, the mean WSAS was $22.60(8.56)$. In addition, the GSI was $1.54(\mathrm{SD}=0.66)$ and IIP was $1.65(\mathrm{SD}=0.52)$. All these measures reflect a poorly functioning patient group with a high level of symptom and interpersonal distress. TA was measured using the revised short form of the Working Alliance Inventory (WAI-SR). The patients filled out the WAI-SR at the same intervals as did the therapists when filling out the FWC-12 (i.e., every 6 months from 6 months up to 2.5 years in their treatment period, with a final assessment at the end of the treatment).

- Insert Table 1 approx. here-

- Insert Table 2 approx. here-

\section{Assessment}

\section{The FWC}

The FWC is a self-report measure in which therapists rate their emotional responses toward a patient in a five-point response format ( $0-4)$, ranging from 'No such feeling' (0) to 'Very much' (4). The present study uses a short version of the Feeling Word Checklist 58 (FWC-58) that includes 12 items (FWC-12). In the FWC-12, the prompt, 'During recent conversations with the patient I have felt...' is followed by the 12 feeling words: Disliked, Important, Threatened, Exalted, Bored, Confident, Inadequate, Admired, On Guard, Calm, Invaded and Overview. Each of the words is rated from 0 to 4 by therapists, based on how acutely they experience each feeling.

The FWC-12 is new and was constructed for this study with the aim of creating a more applicable and less time-consuming questionnaire, reflecting some positive and some negative feelings. The aim in its creation is to determine whether these positive and negative feelings are important cues to describe therapy processes and outcomes in future studies. The items were selected from the FWC -58 partly using a data-driven method based on former factor analyses of the FWC- $58(15,17)$ and partly as a result of clinical considerations.

\section{Diagnostics}

All patients were diagnosed according to DSM-IV (29) using the Mini International Neuropsychiatric Interview (MINI) (34) for symptom disorders and the Structured Clinical Interview for DSM-IV-Axis II 
(SCID-II) for PD (35). Diagnostic reliability was not investigated. However, diagnostic assessments were performed in each unit by clinical staff who had received systematic training in diagnostic interviews and principles of the Longitudinal, Expert, All-Data (LEAD) procedure $(36,37)$. This means that diagnoses were based on all available information, including referral letters, self-reported history, complaints, overall clinical impression and the results of the two diagnostic interviews (i.e., the MINI and SCID-II). In DSM-IV, the classification of PD is polythetic-that is, the criteria within each disorder are neither necessary nor sufficient. The number of fulfilled PD criteria can thus be seen as a reflection of the dimensional strength or closeness to prototypic PD constructs.

\section{TA}

The patients filled in the WAI-SR $(38,39)$ every six months during treatment and at discharge from treatment. The WAI-SR is a 12-item questionnaire representing 3 different aspects of the patient's relationship to the therapist; bond, task and goal. Patients are asked to judge each question on a Likert scale from 'Never' (1) to 'Always' (7). The patients filled out two versions of the WAI-SR: one with reference to their group therapist (WAI-G) and one with reference to their individual therapist (WAI-I).

\section{Statistics}

\section{Unbalanced Sample}

The data of the current study are based on ordinary routine assessments, but it is important to note that these routines sometimes fail for one reason or another. Sometimes therapists fail to fill out FWC-12 at the proper time, and sometimes administrative routines fail so that the patients do not get their six-month questionnaires. As such, the dataset in the current study is unbalanced. See Table 2 for an assessment of the FWC-12 and WAI-SR.

\section{Factor Analysis}

We decided to analyse the FWC-12 after 12 months of therapy, assuming that therapy is well underway by that point. There is usually also some delay from the initial assessment period to inclusion in the treatment programme, although all patients have some kind of individual clinical contact with the unit during this waiting time. As such, there is good reason to assume that the treatment process has stabilised one year after the initial assessment.

The total sample of 2,425 patients was first randomly divided into 2 separate sub-samples. This was done to facilitate the exploratory (EFA) and confirmatory factor analysis (CFA). The first sub-sample ( $n=$ $1,219)$ was used to conduct explorative factor analyses and the second $(n=1,206)$ to cross-validate the suggested factor structure in a confirmatory factor analysis. After 1 year of therapy, the number of completed FWC-12 questionnaires gathered was 869 . With respect to the initial factor analysis, sub- 
sample 1 comprised 439 FWC-12 questionnaires and sub-sample 2 comprised $430 \mathrm{FWC}-12$ questionnaires. All other analyses are based on the total sample of 2,425 questionnaires.

Using IBM SPSS Statistics for Windows, Version 25 (2017), randomisation of the total sample was done with the Select function (approximate 50\%). Group differences were analysed using an independent samples t-test (two-sided). Effect sizes of group differences were estimated using Hedges' g (40). Relationships between variables were estimated by multiple linear regression analysis, and scale reliability was estimated using Cronbach's alpha (41). EFA and CFA were conducted using Mplus 7.11 (Muthén \& Muthén, Los Angeles, CA, USA) (42), with estimations based on the maximum likelihood (ML) and maximum likelihood mean (MLM) adjusted functions, respectively. The mean-adjusted chi-square test statistic, also referred to as the Satorra-Bentler chi-square (43) is robust to non-normality.

To evaluate the CFA models, goodness of fit was estimated by root mean square error of approximation (RMSEA) (44), the non-normed fit index (NFI) (45)-also called the Tucker Lewis Index (TLI) (46)-the comparative fit index (CFI) (47) and the standardised root mean square residual (SRMR) (48).

An RMSEA of 0.05 or below indicates a good model fit, values between 0.05 and 0.08 indicate a reasonable fit, values between 0.08 and 0.10 indicate a mediocre fit and values above 0.10 indicate an unacceptable fit (49). However, a cut-off value close to 0.06 (48) or a stringent upper limit of 0.07 (50) seem to be the general consensus of what is considered acceptable. The TLI and CFI both measure model fit in comparison to the independence model. Both are derived from the chi-square statistic and are supposed to lie between 0 and 1 . Values greater than 0.90 for these measures are normally required for good fit of a model, although Hu and Bentler (48) have suggested TLI $\geq 0.95$ as the threshold. The SRMR is the mean absolute value of the covariance residuals, and it ranges from 0 to 1 . Well-fitting models should obtain values less than $0.05(51,52)$, but values up to 0.08 are acceptable $(48)$.

\section{Results}

\section{Factor Analyses}

\section{Factor Structure of the FWC-12}

The EFA of sub-sample 1 ( $n=436$ at 1 year) indicated four factors with eigenvalues above 1.0, accounting for $67 \%$ of the observed variance. The fifth factor had an eigenvalue of 0.716 , accounting for $6 \%$ of the remaining observed variance. The CFA of sub-sample $2(n=424$ at 1 year), based on the suggested four-factor model from the EFA, had a chi-square model fit of 99.533 (degrees of freedom [df]: 48; $p=0.0000$ ) and an RMSEA (90\% confidence interval [CI]), CFI, TLI and SRMR of 0.050 (0.036-0.064), $0.948,0.929$ and 0.054 , respectively, indicating perfect fit. A subsequent CFA based on the sub-samples 1 and 2 combined ( $\mathrm{n}=860$ at 1 year) also revealed good model fit. However, factor three comprised only two items (Bored and Inadequate),, and Bored had a high degree of residual variance (86\%). Moreover, one item of factor two (Threatened) stood out, with a considerable lack of variance (mean: 0.05; SD: 0.28; 
Skewness: 6.24; Kurtosis: 45.46) -that is, it a hardly a strongly endorsed feeling. Based on these findings, Bored and Threatened were omitted from the item pool, and Inadequate was moved to factor two. The solution was then a three-factor solution based on 10 items/feelings, labelled Idealised, Inadequate and Confident. See Table 3 for the final operationalisation of the three-factor model and estimates of scale reliabilities. As shown in Table 3, the scale reliabilities are in the acceptable range (i.e., at or above 0.70 ), except for the factor Inadequate.

- Insert Table 3 approx. here-

From the CFA of the new three-factor model, it was reasonable to conduct two modifications. The first was to accept a negative cross-loading from the item Important to the factor Inadequate, and the second was to accept a negative residual covariance between the item Inadequate with the item Overview of the factor Confident. In Table 4, model fit indices are shown for all assessment periods from six months to end of treatment. From this, all fit indices indicate excellent to good fit to the model, except from FWC evaluations at 2.5 years. The main reason for this indication of misfit a cross-loading of the item Invaded with the factor Idealised. By accepting this cross-loading in a modified specification, the model fit was found to be acceptable (RMSEA $=0.074 ; \mathrm{CFI}=0.937 ; \mathrm{TLI}=0.902$ ). Based on these considerations, we concluded that this three-factor structure was the best model.

- Insert table 4 approx. here -

\section{Validity}

Table 5 shows the mean levels of the three FWC scales across gender and selected PD. The mean values after 1 year of therapy was highest for Confident (mean $=2.74 ; \mathrm{SD}=0.74)$, followed by Idealised $($ mean $=$ $1.12 ; \mathrm{SD}=0.79)$ and Inadequate $($ mean $=0.47 ; \mathrm{SD}=0.50)$.

To further validate the CT factors, we explored the relationship between the factors, the number of PD criteria, and TA. As shown in Table 6, Confident correlated negatively with the total number of PD criteria. Inadequate had a positive correlation with total number of PD criteria, and the borderline, narcissistic and paranoid PD criteria. Idealised showed a positive correlation with borderline and histrionic PD criteria. The avoidant PD criteria showed a weak, but not significant, positive correlation with Confident.

Patient-rated TA showed a positive correlation with Confident and a negative correlation with Inadequate. Idealised had a positive correlation with evaluation of the individual therapists (WAI-I) but not with evaluation of the group therapists (WAI-G).

- Insert table 5 approx. here-

- Insert table 6 approx. here -

\section{Discussion}


The main objective of the current study was to investigate the factor structure and psychometric properties of the FWC-12. We found 10 items that constituted three CT factors, namely, Idealised, Inadequate and Confident. The factors were psychometrically acceptable and clinically recognisable and can be seen as aspects of CT feelings that can be evoked when treating PD patients.

There are conceptual similarities between the present factors and several of those found in other studies. Holmquist et al. (14) were the first to examine the underlying factor structure of FWC applied in individual psychotherapy. They used an FWC with 48 feeling words (FWC-48) and found four factors to be evoked: Positive, Negative, Distant and Dejected. The factor Positive seems to show similarities with the factor Confident in our study. Negative and Dejected seem to show similarities with Inadequate. Dahl et al. (17) used a version with 58 feeling words (FWC-58) and found four factors; two of these (Confident and Inadequate) conceptually overlap with our study. The same holds for the factors Confident and Inadequate in the study by Ulberg et al. (18) (FWC-24), and the factor Inadequate in that of Lindquist et al. (9) (FWC-24). Further, in studies where the setting is inpatient care, Røssberg et al. (15) found seven factors, two of which (Inadequate and Confident) conceptually overlap with ours (FWC-58). However, we cannot say that the factors mentioned above are directly comparable, as different studies have used different FWC questionnaires (18) and included different patient populations. Idealised is a factor not reported in previous studies on FWC, but similarities between some of the previous factors reported in other studies, such as Important in the study by Røssberg et al. (15), can be identified. Nevertheless, few studies on FWC seem to have captured this aspect of CT. For an overview of previous FWC studies, see Lindquist et al. (9).

It is noteworthy that the therapists overall score their CT feelings as low in intensity. The mean scores range from 0.47 (Inadequate) to 1.12 (Idealised) to 2.74 (Confident).. The scores are in a similar range to that seen in many other FWC studies-that is, quite low scores are consistently reported $(9,14,17,18)$. However, the patients in the present study are mainly poorly functioning PD patients, and one might have expected stronger feelings to be reported. It is also somewhat surprising that Confident is the feeling assigned the highest score. This could be due to the therapists overall being highly experienced and the fact that regular group supervision is part of the therapists' work, in which CT is a focus. This is in line with the report of Ulberg et al. (18), in which Confident was positively associated with more experience as well as with an increased level of supervision-that is, they found lower levels of Inadequate feelings with more supervision.

Another explanation might be that the questionnaires were only filled in every six months. Some therapists have reported that 'overall' they feel relatively confident in meeting with the patient when they look at the relationship over a long period of time. More frequent measurements could likely capture more varied and possibly more intense CT feelings. Alternatively, the result could also be due to 'defensive bias', which is a potential weakness that all self-report questionnaires share. Some therapists may find it difficult to report negative feelings, whether because they find it unprofessional or because they are simply not conscious of the negative feelings. 
The three factors, Idealised, Inadequate and Confident, are consistent with aspects of feeling responses when working with PD patients both described in the clinical literature $(54,55)$ and in the existing empirical literature $(5,24)$. Specifically, we found that-especially in meeting with patients who meet many borderline PD criteria-therapists feel more idealised and more inadequate. We also found that the total number of PD criteria correlated positively with the Inadequate factor. This is in line with the report of Dahl et al. (17). One could object that it is a weakness that feelings evoked by the avoidant PD patient group are not better captured in the FWC-12. Avoidant PD and borderline PD constitute the two largest patient groups in this material. The avoidant PD criteria showed a weak, but not significant, positive correlation with a Confident response. Previous empirical studies have reported that Confident is the most significant response from the group in question (16). However, this result might also reflect that the avoidant patients are a more heterogeneous patient group. That is, it is possible that there is greater variation in what therapist feel when treating these patients. From a clinical perspective, there is reason to believe that therapists may experience more negative feelings than previous studies have reported.

Correlational analyses with patient-rated TA revealed several meaningful and significant associations. Patient-rated TA, measured using the WAI-SR, showed a positive correlation with Confident and a negative correlation with Inadequate. This is in line with the study by Dahl et al. (17), although they rated patients' TA with a different instrument, called the Help and Understanding Scale (HUS). The correlations between patient-rated TA and CT is of particular interest because of the non-overlapping perspectives. Idealised correlated positively with patients' evaluation of their individual therapist (WAI-I) but not with their group therapist (WAI-G). From a clinical experience, it is not very surprising that the individual therapist is idealised more than the group therapist. In treatment programs involving both individual and group therapy, patients must share a therapist's attention with up to seven others during group therapy, making way for more complicated feelings such as envy, feelings of exclusion and feelings of being alone among others; as such, the therapist's lack of omnipotence is more striking than it is in individual sessions. As far as is known, no other empirical studies have found this association. However, the results from the correlational analysis with TA should also take into account that the patients' reports are not blind to the therapists. Thus, there is a possibility that there is some bias with respect to the patients' self-report reflecting their satisfaction with their therapists.

\section{Strengths and Limitations}

A considerable strength of this study is that the sample was large enough to be divided in two, for EFA and subsequent CFA, and that each of the sub-samples was large enough to yield stability in the estimates. Another strength is that the data comprise a large and representative sample of patients with PD and PD traits, wherein PD not otherwise specified (NOS), borderline PD and avoidant PD are the most prevalent diagnoses. The patient sample is also well described, representing a functionally impaired and highly symptomatic patient group-a group known to evoke powerful CT reactions in therapists. No previous studies on PD and CT have investigated CT using such a large sample of poorly functioning patients. This study can thus contribute to illuminating feelings that are typically described in clinical 
literature but empirically investigated to a small extent. However, the poorly functioning patients in this study may also restrict the generalisation of the results to other clinical samples.

One of the main limitations is that we do not know the number of therapists participating in the study. Additionally, the therapists did not necessarily score FWCs for each patient at every required assessment time (i.e., every six months for that patient). However, data from 13 different treatment units in Norway were collected, and there is reason to believe that the number of therapists is relatively high due to the number of units assessed, which can be regarded as a strength.

\section{Conclusion}

In this study, we found that the FWC-12 comprised three factors, labelled Inadequate, Idealised and Confident. The subscales had satisfactory internal consistency and were meaningfully related to patients' personality pathology and TA. Thus, this shorter list of feeling words seems to identify common experiences evoked in meetings with patients with PD and may prove valuable for further research, as well as for use in clinical and educational contexts.

\section{Abbreviations}

CFA: Confirmatory Factor Analysis; CFI: Comparative Fit Index; CIP: Circumplex of Interpersonal Problems; CT: Countertransference; df: Degree of Freedom; DSM-IV: Diagnostic and Statistical Manual of Mental Disorders Version 4; EFA: Exploratory Factor Analysis; FWC: Feeling Word Checklist; GAF: Global Assessment Of Functioning; GSI: Global Severity Index; HUS: Help and Understanding Scale; IIP: Index of Interpersonal Problems; LEAD: Longitudinal, Expert, All-Data; MIIC = Mean Inter-Item Correlation; MINI: Mini International Neuropsychiatric Interview; ML: Maximum Likelihood; MLM: Maximum Likelihood Mean Adjusted; NFI: Non-Normed Fit Index; PD: Personality Disorder; PD NOS: Personality Disorder Not Otherwise Specified; RMSEA: Root Mean Square Error of Approximation; SCID-II: Structured Clinical Interview for DSM-IV-Axis II Personality Disorders; SCL-90-R: Revised Symptom Checklist; SD: Standard Deviation; SRMR: Standardised Root Mean Square Residual; TLI: Tucker Lewis Index; WAI-G: Working Alliance Inventory-Group Therapist; TA: Therapeutic Alliance; WAI-SR: Short Version of Working Alliance Inventory; WAI-I: Working Alliance Inventory-Individual Therapist; WSAS: Work and Adjustment Scale

\section{Declarations}

\section{Ethics Approval and Consent to Participate}

All patients are informed that data from their routine assessments will be used anonymously in clinical research, with an opportunity to deny. Patients in the current study have given their written consent to participate in the research. The different treatment units collected patient data, which were registered in an anonymous central database, administrated by the Department for Personality Psychiatry, Oslo University Hospital. Since this study is based on anonymous routine data, it is of no issue for The State 
Data Inspectorate and a statement of ethics approval was not required by the Regional Committees for Medical and Health Research Ethics in Norway.

\section{Consent for Publication}

Not applicable.

\section{Availability of data and materials}

Due to restrictions imposed by the Regional Medical Ethics Committee regarding patient confidentiality, data are available upon request. Requests for data may be sent to the hospital's Privacy and Data Protection Officer at: personvern@ous-hf.no

\section{Competing Interests}

None of the aforementioned authors has any financial disclosure or other conflict of interest related to this manuscript.

\section{Funding}

No funding was obtained for this study

\section{Authors' Contributions}

RB: data analysis and drafting and revising the manuscript; TW: revising the manuscript; JE: revising the manuscript; JIR: revising the manuscript; HSD: revising the manuscript; GP: data analysis and drafting and revising the manuscript. All authors read and approved the final manuscript.

\section{Acknowledgements}

We wish to thank the patients and staff of the Norwegian Network of Personality-Focused Treatment Programs for their contribution to this study.

\section{References}

1.Freud S, Strachey J, Freud A. The standard edition of the complete psychological works of Sigmund Freud Vol. 11 (1910): five lectures on psycho-analysis, Leonardo da Vinci, and other works. London: Hogarth Press and the Institute of Psychoanalysis; 1957. 
2.Winnicott D. Hate in the counter-transference. Int J Psychoanal. 1949;30:69.

3.Heimann P. On counter-transference. Int J Psychoanal. 1950;31:81.

4.Gabbard GO. Psychodynamic psychiatry in clinical practice. Washington, DC: American Psychiatric Association Publishing; 2014.

5.Betan E, Heim AK, Zittel Conklin C, Westen D. Countertransference phenomena and personality pathology in clinical practice: an empirical investigation. Am J Psychiatry. 2005;162(5):890-8.

6.Fauth J. Toward more (and better) countertransference research. Psychotherapy. 2006;43(1):1-31.

7. Hayes JA, Gelso CJ, Goldberg S, Kivlighan DM. Countertransference management and effective psychotherapy: meta-analytic findings. Psychotherapy. 2018;55(4):496-507.

8.Tanzilli A, Colli A, Del Corno F, Lingiardi V. Factor structure, reliability, and validity of the Therapist Response Questionnaire. Personal Disord. 2016;7(2):147-58.

9.Lindqvist K, Falkenstrom F, Sandell R, Holmqvist R, Ekeblad A, Thoren A. Multilevel exploratory factor analysis of the Feeling Word Checklist-24. Assessment. 2017;24(7):907-18.

10.Whyte CR, Constantopoulos C, Bevans HG. Types of countertransference identified by Q-analysis. Br J Clin Psychol. 1982;55(2):187-201.

11.Loffler-Stastka H, Sell C, Zimmermann J, Huber D, Klug G. Is countertransference a valid source of clinical information? Investigating emotional responses to audiotaped psychotherapy sessions. Bull Menninger Clin. 2019:1-23.

12.Rosenberger EW, Hayes JA. Origins, consequences, and management of countertransference: a case study. J Couns Psychol. 2002;49(2):221-32.

13.Ligiéro DP, Gelso CJ. Countertransference, attachment, and the working alliance: the therapist's contribution. Psychotherapy. 2002;39(1):3-11.

14. Holmqvist R, Hansjons-Gustafsson U, Gustafsson J. Patients' relationship episodes and therapists' feelings. Psychol Psychother. 2002;75(4):393-409.

15.Rossberg Jl, Hoffart A, Friis S. Psychiatric staff members' emotional reactions toward patients. A psychometric evaluation of an extended version of the Feeling Word Checklist (FWC-58). Nordic $J$ Psychiatry. 2003;57(1):45-53.

16.Colli A, Ferri M. Patient personality and therapist countertransference. Curr Opin Psychiatry. 2015;28(1):46-56. 
17.Dahl HS, Rossberg JI, Bogwald KP, Gabbard GO, Hoglend PA. Countertransference feelings in one year of individual therapy: an evaluation of the factor structure in the Feeling Word Checklist-58. Psychother Res. 2012;22(1):12-25.

18.Ulberg R, Falkenberg A, Naerdal T, Johannessen H, Olsen J, Eide T, et al. Countertransference feelings when treating teenagers. A psychometric evaluation of the Feeling Word Checklist-24. Am J Psychother. 2013;67(4):347-58.

19.Daniel SIF, Lunn S, Poulsen S. Client attachment and therapist feelings in the treatment of bulimia nervosa. Psychotherapy. 2015;52(2):247-57.

20.Machado Dde B, Coelho FM, Giacomelli AD, Donassolo MA, Abitante MS, Dall'Agnol T, et al. Systematic review of studies about countertransference in adult psychotherapy. Trends Psychiatry Psychother. 2014;36(4):173-85.

21.Machado DdB, Teche SP, Lapolli C, Tavares BF, Almeida LSPd, Silva GBD, et al. Countertransference and therapeutic alliance in the early stage of adult psychodynamic psychotherapy. Trends Psychiatry Psychother. 2015;37(3):133-42.

22.Kernberg OF. Psychodynamic psychotherapy of borderline patients. New York: Basic Books; 1989.

23.Rossberg Jl, Karterud S, Pedersen G, Friis S. An empirical study of countertransference reactions toward patients with personality disorders. Compr Psychiatry. 2007;48(3):225-30.

24.Colli A, Tanzilli A, Dimaggio G, Lingiardi V. Patient personality and therapist response: an empirical investigation. Am J Psychiatry. 2014;171(1):102-8.

25.Gazzillo F, Lingiardi V, Del Corno F, Genova F, Bornstein RF, Gordon RM, et al. Clinicians' emotional responses and psychodynamic diagnostic manual adult personality disorders: a clinically relevant empirical investigation. Psychotherapy. 2015;52(2):238-46.

26.Tanzilli A, Lingiardi V, Hilsenroth M. Patient SWAP-200 personality dimensions and FFM traits: do they predict therapist responses? Personal Disord. 2018;9(3):250-62.

27.Najavits LM, Griffin ML, Luborsky L, Frank A, Weiss RD, Liese BS, et al. Therapists' emotional reactions to substance abusers: a new questionnaire and initial findings. Psychotherapy. 1995;32(4):669-77.

28.Karterud S, Pedersen G, Bjordal E, Brabrand J, Friis S, Haaseth O, et al. Day treatment of patients with personality disorders: experiences from a Norwegian treatment research network. J Personal Disord. 2003;17(3):243.

29.Diagnostic and statistical manual of mental disorders: DSM-IV. 4th ed. Washington, DC: American Psychiatric Association; 1994. 
30.Mundt JC, Marks IM, Shear MK, Greist JM. The Work and Social Adjustment Scale: a simple measure of impairment in functioning. Br J Psychiatry. 2002;180:461-4.

31.Derogatis LR. Symptom Checklist-90-R (SCL-90-R): administration, scoring and procedures manual. Minneapolis, MN: National Computer System; 1994.

32.Alden LE, Wiggins JS, Pincus AL. Construction of circumplex scales for the Inventory of Interpersonal Problems. J Pers Assess. 1990;55(3-4):521-36.

33.Pedersen, GA. Norsk revidert versjon av Inventory of Interpersonal Problems-Circumplex (IIP-C) [Revised Norwegian version of the Inventory of Interpersonal Problems-Circumplex (IIP-C)]. Tidsskrift for Norsk Psykologforening. 2002;39(1):25-34.

34.Sheehan D, Lecrubier Y, Janavs J. Mini-International Neuropsychiatric Interview (MINI). Tampa, FL: University of South Florida, Institute for Research in Psychiatry; 1994.

35.First MB. User's guide for the structured clinical interview for DSM-IV Axis II personality disorders: SCID-II. Washington, DC: American Psychiatric Press; 1997.

36.Spitzer RL. Psychiatric diagnosis: are clinicians still necessary? Compr Psychiatry. 1983;24(5):399411.

37.Pedersen G, Karterud S, Hummelen B, Wilberg T. The impact of extended longitudinal observation on the assessment of personality disorders. Personal Ment Health. 2013;7(4):277-87.

38. Horvath AO, Greenberg LS. Development and validation of the Working Alliance Inventory. J Couns Psychol. 1989;36(2):223-33.

39. Hatcher RL, Gillaspy JA. Development and validation of a revised short version of the Working Alliance Inventory. Psychother Research. 2006;16(1):12-25.

40. Hedges LV. Distribution theory for Glass's estimator of effect size and related estimators. J Educ Stat. 1981;6(2):107-28.

41.Cronbach L. Coefficient alpha and the internal structure of tests. Psychometrika. 1951;16(3):297-334.

42.Muthén LK, Muthén, BO. Mplus user's guide. 7th ed. Los Angeles, CA: Muthèn \& Muthèn; 1998.

43.Satorra A, Bentler P. A scaled difference chi-square test statistic for moment structure analysis. Psychometrika. 2001;66(4):507-14.

44.Steiger JH. Structural model evaluation and modification: an interval estimation approach. Multivariate Behav Res. 1990;25(2):173-80. 
45.Bentler PM, Bonett DG. Significance tests and goodness of fit in the analysis of covariance structures. Psychol Bull. 1980;88(3):588-606.

46.Tucker LR, Lewis C. A reliability coefficient for maximum likelihood factor analysis. Psychometrika. 1973;38(1):1-10.

47.Bentler PM. Comparative fit indexes in structural models. Psychol Bull. 1990;107(2):238-46.

48. Hu LT, Bentler PM. Cutoff criteria for fit indexes in covariance structure analysis: conventional criteria versus new alternatives. Struct Equ Modeling. 1999;6(1):1-55.

49.MacCallum RC, Browne MW, Sugawara HM. Power analysis and determination of sample size for covariance structure modeling. Psychol Methods. 1996;1(2):130-49.

50. Steiger $\mathrm{JH}$. Understanding the limitations of global fit assessment in structural equation modeling. Pers Individ Dif. 2007;42(5):893-8.

51.Byrne BM. Structural equation modeling with EQS: basic concepts, applications, and programming. 2nd ed. Mahwah, NJ: Lawrence Erlbaum Associates Publishers; 2013.

52.Diamantopoulos A. Introducing LISREL: a guide for the unintiated. London: SAGE Publications Ltd.; 2000 .

53.Gabbard GO. The treatment of the 'special' patient in a psychoanalytic hospital. 1986;13(3):333-47.

54.Klein M. Notes on some schizoid mechanisms. Int J Psychoanal. 1996;5(2):160.

\section{Tables}


Table 1.

Prevalence of $P D$ and range of $P D$ criteria.

\begin{tabular}{|l|c|c|}
\hline \multicolumn{2}{|l|}{ Prevalence of PDs (\%) } & Median number of PD criteria (range) \\
\hline Schizoid & $9(0 \%)$ & $0(0-5)$ \\
\hline Schizotypal & $1(0 \%)$ & $0(0-7)$ \\
\hline Paranoid & $158(7 \%)$ & $1(0-7)$ \\
\hline Antisocial & $14(1 \%)$ & $0(0-5) *$ \\
\hline Narcissistic & $10(1 \%)$ & $0(0-8)$ \\
\hline Borderline & $489(23 \%)$ & $2(0-9)$ \\
\hline Histrionic & $1(0 \%)$ & $0(0-5)$ \\
\hline Avoidant & $721(33 \%)$ & $2(0-7)$ \\
\hline Dependent & $82(5 \%)$ & $1(0-7)$ \\
\hline Obsessive-compulsive & $113(5 \%)$ & $0(0-7)$ \\
\hline PD NOS & $345(16 \%)$ & $8(0-22)$ \\
\hline No PD & $626(29 \%)$ & $0(0-16)$ \\
\hline PD diagnosis deferred & $258(11 \%)$ & - \\
\hline
\end{tabular}

Note. PD NOS = personality disorder not otherwise specified.

*Adult antisocial criteria

Table 2.

FWC-12 assessments at different times.

\begin{tabular}{|l|c|}
\hline \multicolumn{2}{|l|}{ Number of FWC-12 assessments completed by therapists } \\
\hline 6 months & 806 \\
\hline 1 year & 869 \\
\hline 1.5 years & 606 \\
\hline 2 years & 412 \\
\hline 2.5 years & 266 \\
\hline End of treatment & 1890 \\
\hline
\end{tabular}




\section{Table 3.}

Three-factor model of FWC items assessed one year after initial assessment and estimates of scale reliability at each assessment point.

\begin{tabular}{|c|c|c|c|}
\hline & \multicolumn{3}{|c|}{ Factors and loadings based on one-year evaluations } \\
\hline Items / feeling words & Idealised & Inadequate & Confident \\
\hline Important & \multicolumn{2}{|l|}{0.575} & \\
\hline Exalted & \multicolumn{2}{|l|}{0.867} & \\
\hline Admired & \multicolumn{2}{|l|}{0.851} & \\
\hline Disliked & \multicolumn{2}{|r|}{0.573} & \\
\hline Inadequate & \multicolumn{2}{|r|}{0.615} & \\
\hline On Guard & \multicolumn{2}{|r|}{0.576} & \\
\hline Invaded & \multicolumn{2}{|r|}{0.568} & \\
\hline Confident & & & 0.722 \\
\hline Calm & & & .876 \\
\hline Overview & & & .581 \\
\hline Evaluations & \multicolumn{3}{|c|}{ Cronbach's alpha (95\% CI; MIIC) } \\
\hline 6 months & $0.80(0.78-0.83 ; 0.58)$ & $0.62(0.58-0.66 ; 0.3$ & $0.73(0.70-0.76 ; 0.48)$ \\
\hline 1 year & $0.78(0.76-0.81 ; 0.56)$ & $0.65(0.61-0.69 ; 0.3$ & $0.77(0.74-0.79 ; 0.53)$ \\
\hline 1.5 years & $0.80(0.77-0.82 ; 0.57)$ & $0.66(0.61-0.70 ; 0.3$ & $0.78(0.75-0.81 ; 0.55)$ \\
\hline 2 years & $0.78(0.74-0.82 ; 0.55)$ & $0.66(0.56-0.68 ; 0.3$ & $0.79(0.75-0.82 ; 0.55)$ \\
\hline 2.5 years & $0.77(0.72-0.82 ; 0.54)$ & $0.70(0.64-0.76 ; 0.4$ & $0.76(0.71-0.81 ; 0.51)$ \\
\hline End of treatment & $0.81(0.79-0.82 ; 0.60)$ & 0.71 (0.69-0.73; 0.4 & $0.78(0.77-0.80 ; 0.54)$ \\
\hline
\end{tabular}

Note. $\mathrm{CI}=$ confidence interval; $\mathrm{MIIC}=$ mean inter-item correlation. 


\section{Table 4.}

Goodness-of-fit statistics from CFA based on the three-factor model of FWC-10 questionnaires at different time points.

\begin{tabular}{|l|c|c|c|c|c}
\hline Evaluations & $X^{2}(\mathrm{df})$ & $R M S E A(90 \%$ CI $)$ & $C F I$ & $T L I$ & $S R M R$ \\
\hline 6 months & $83.37(30)$ & $0.047(0.035-0.060)$ & 0.969 & 0.954 & 0.043 \\
\hline 1 year & $91.92(30)$ & $0.049(0.038-0.061)$ & 0.971 & 0.957 & 0.037 \\
\hline 1.5 years & $114.34(00)$ & $0.069(0.055-0.082)$ & 0.944 & 0.917 & 0.050 \\
\hline 2 years & $76.56(30)$ & $0.062(0.045-0.079)$ & 0.956 & 0.934 & 0.053 \\
\hline 2.5 years & $84.16(30)$ & $0.083(0.062-0.104)$ & 0.918 & 0.877 & 0.060 \\
\hline End of treatment & $214.86(30)$ & $0.58(0.050-0.065)$ & 0.965 & 0.948 & 0.044 \\
\hline
\end{tabular}

Note. Chi-square statistics: $\mathrm{p}$ values $<.0001 . \mathrm{CFA}=$ confirmatory factor analysis; $\mathrm{CFI}=$ comparative fit index; CI = confidence interval; RMSEA = root mean square error of approximation; SRMR = standardised root mean square residual; TLI $=$ Tucker-Lewis Index. 
Table 5.

Descriptive statistics of FWC subscales.

\begin{tabular}{|c|c|c|c|}
\hline & $\begin{array}{c}\text { Idealised } \\
\text { Mean (SD) }\end{array}$ & $\begin{array}{l}\text { Inadequate } \\
\text { Mean (SD) }\end{array}$ & $\begin{array}{c}\text { Confident } \\
\text { Mean (SD) }\end{array}$ \\
\hline \multicolumn{4}{|l|}{ Total sample } \\
\hline Total sample & $1.12(0.78)$ & $0.47(0.50)$ & $2.74(0.74)$ \\
\hline Males & $1.11(0.80)$ & $0.50(0.50)$ & $2.73(0.72)$ \\
\hline Females & $1.12(0.78)$ & $0.47(0.50)$ & $2.74(0.75)$ \\
\hline \multicolumn{4}{|l|}{ Diagnostic sub-groups ${ }^{a}$} \\
\hline No PD $(n=195)$ & $1.06(0.74)$ & $0.40(0.44)$ & $2.84(0.72)$ \\
\hline Paranoid PD (n = 62) & $1.15(0.82)$ & $0.60(0.60)$ & $2.72(0.63)$ \\
\hline Borderline PD ( $\mathrm{n}=232)$ & $1.27(0.87)$ & $0.62(0.58)$ & $2.59(0.76)$ \\
\hline Avoidant PD $(\mathrm{n}=289)$ & $1.06(0.76)$ & $0.44(0.48)$ & $2.77(0.73)$ \\
\hline Dependent PD $(\mathrm{n}=40)$ & $1.16(0.71)$ & $0.45(0.35)$ & $2.80(0,77)$ \\
\hline Obsessive-Compulsive PD $(n=50)$ & $0.97(0.69)$ & $0.55(0.61)$ & $2.65(0.79)$ \\
\hline PD NOS ${ }^{b}$ & $1.13(0.77)$ & $0.47(0.46)$ & $2.71(0.68)$ \\
\hline
\end{tabular}

Note: FWC assessed at one year. PD NOS = PD not otherwise specified.

${ }^{a}$ No correction for comorbidity among PDs; only PDs represented by more than ten cases were listed. 


\section{Table 6.}

Correlations between the FWC-10 and other clinical measures.

\begin{tabular}{|c|c|c|c|}
\hline & Idealised & Inadequate & Confident \\
\hline \multicolumn{4}{|l|}{ Number of PD criteria } \\
\hline Schizotypal & 0.006 & 0.066 & $-0.104 * *$ \\
\hline Schizoid & -0.066 & 0.007 & $-0.091 * *$ \\
\hline Paranoid & 0.020 & $0.137 * *$ & -0.046 \\
\hline Antisocial (adult criteria) & 0.033 & $0.074 *$ & 0.006 \\
\hline Narcissistic & 0.035 & $0.125^{* *}$ & $-0.075^{*}$ \\
\hline Histrionic & $0.116^{* *}$ & 0.057 & -0.030 \\
\hline Borderline & $0.101 * *$ & $0.245^{* *}$ & $-0.168 * *$ \\
\hline Avoidant & -0.054 & -0.054 & 0.017 \\
\hline Dependent & 0.020 & 0.044 & -0.044 \\
\hline Obsessive-Compulsive & 0.007 & 0.064 & -0.011 \\
\hline Total number of PD criteria ${ }^{a}$ & 0.046 & $0.171^{* *}$ & $-0.117^{* *}$ \\
\hline \multicolumn{4}{|l|}{ Working Alliance Inventory } \\
\hline \multicolumn{4}{|c|}{ Evaluation of group therapists (WAI-G) } \\
\hline Goals & 0.019 & $-0.196^{* *}$ & $0.124^{* *}$ \\
\hline Tasks & 0.028 & $-0.211^{* *}$ & $0.153^{* *}$ \\
\hline Bond & -0.023 & $-0.185^{* *}$ & $0.113^{* *}$ \\
\hline \multicolumn{4}{|c|}{ Evaluation of individual therapists (WAI-I) } \\
\hline Goals & $0.086^{*}$ & $-0.260^{* *}$ & $0.160 * *$ \\
\hline Tasks & $0.119 * *$ & $-0.226^{* *}$ & $0.190 * *$ \\
\hline Bond & 0.071 & $-0.264 * *$ & $0.193 * *$ \\
\hline
\end{tabular}

Note: FWC and WAI assessed at one year.

${ }^{a}$ Antisocial PD criteria for child and adulthood omitted.

*Correlation is significant at the 0.05 level (2-tailed).

${ }^{* *}$ Correlation is significant at the 0.01 level (2-tailed). 